\title{
Article
}

\section{Is Gaydar Affected by Attitudes Towards Homosexuality? Confidence, Labelling Bias, and Accuracy}

Brewer, Gayle and Lyons, Minna

Available at http://clok.uclan.ac.uk/15998/

Brewer, Gayle ORCID: 0000-0003-0690-4548 and Lyons, Minna (2016) Is Gaydar Affected by Attitudes Towards Homosexuality? Confidence, Labelling Bias, and Accuracy. Journal of Homosexuality . ISSN 0091-8369

It is advisable to refer to the publisher's version if you intend to cite from the work. http://dx.doi.org/10.1080/00918369.2016.1244443

For more information about UCLan's research in this area go to http://www.uclan.ac.uk/researchgroups/ and search for < name of research Group>.

For information about Research generally at UCLan please go to http://www.uclan.ac.uk/research/

All outputs in CLoK are protected by Intellectual Property Rights law, including Copyright law. Copyright, IPR and Moral Rights for the works on this site are retained by the individual authors and/or other copyright owners. Terms and conditions for use of this material are defined in the policies page.

\section{CLoK}

Central Lancashire online Knowledge www.clok.uclan.ac.uk

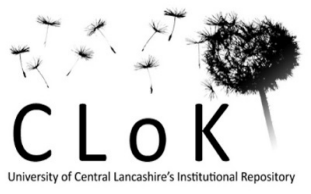




\section{Is Gaydar affected by attitudes towards homosexuality? Confidence, labelling bias, and accuracy}

Gayle Brewer \& Minna Lyons

Previous research has largely ignored the relationship between sexual orientation judgement accuracy, confidence, and attitudes towards homosexuality. In an online study, participants $(N=269)$ judged the sexual orientation of homosexual and heterosexual targets presented via a series of facial photographs. Participants also indicated their confidence in each judgement and completed the Modern Homonegativity Scale (Morrison \& Morrison, 2002). We found that (i) homosexual men and heterosexual women were more accurate when judging photographs of women, as opposed to photographs of men, and (ii) in heterosexual men, negative attitudes towards homosexual men predicted confidence and bias when rating men's photographs. Findings indicate that homosexual men and heterosexual women are similar in terms of accuracy in judging women's sexuality. Further, especially in men, homophobia is associated with cognitive biases in labelling other men, but does not have a relationship with increased accuracy.

Keywords: attitudes; confidence; discrimination; gaydar; homophobia; sexual orientation. 


\section{Introduction}

Previous research indicates that men and women can detect the sexual orientation of others ("gaydar") at higher than chance accuracy (Lyons, Lynch, Brewer, \& Bruno, 2014; Rule \& Ambady, 2008). Men and women correctly identify the sexual orientation of a target from a range of stimuli including photographs (Rule \& Ambady, 2008), video clips (Ambady, Hallahan, \& Conner, 1999), near subliminal exposure to photographic images (Rule, Ambady, \& Hallett, 2009), body shape or movement (Johnson, Gill, Reichman, \& Tassinary, 2007), and speech (Smyth, Jacobs, \& Rogers, 2003). Ratings are typically more accurate when viewing female compared to male targets (Tabak \& Zayas, 2012) and this accuracy does not depend on the sex or sexual orientation of the rater (Brewer \& Lyons, 2016; although see also Valentova \& Havlicek, 2013 and Valentova, Kleisner, Havlicek, \& Neustupa, 2014 for opposing results). Ratings remain accurate when attempts are made to conceal sexual orientation (Sylva, Rieger, Linsenmeier, \& Bailey, 2010), when facial cues, such as cosmetics or piercings, are removed (Tabak \& Zayas, 2012), and when viewing a proportion of the face only (Rule, Ambady, Adams, \& Macrae, 2008). A range of physical cues may influence the perception of sexual orientation including facial symmetry, perceived masculinity or femininity (Hughes \& Bremme, 2011), and voice pitch (Gaudino, 1994).

Though men and women can detect the sexual orientation of others at higher than chance accuracy, previous research indicates that they are unable to predict their rating accuracy (Rule, et al., 2008) or that the more accurate participants are when rating male sexual orientation from facial photographs, the less accurate they perceive themselves to be (Brambilla, Riva, \& Rule, 2013). However, associations do occur between confidence in rating accuracy and response bias. There is a tendency for observers with low rating confidence to less frequently label male target photographs as homosexual. The opposite 
pattern occurs when viewing female target photographs, such that heterosexual women with low rating confidence are more likely to use the term "gay" (Brewer \& Lyons, 2016).

Few studies have considered those factors (other than sex or sexual orientation) that influence the detection of target sexual orientation or the consequences of this judgement. Labelling an individual (correctly or incorrectly) as homosexual can have important social consequences as homosexual men and women may be subject to prejudice, discrimination, and abuse (Herek, 2009; Toomey \& Russell, 2013). Furthermore, heterosexuals may attempt to create psychological distance between themselves and homosexuals (Tally \& Bettencourt, 2008), and avoid being perceived as homosexual (Falomir-Pichastor \& Mugny, 2009; Herek, 2002) or the object of homosexual desire (Buijs, Hekma, \& Duyvendak, 2009). Hence, even those not engaging in overt discrimination may display a degree of negativity towards homosexual men and women. Factors associated with attitudes to homosexuality, also known as homophobia (Weinberg, 1972), sexual prejudice (Herek, 2004), and homonegativity (Stulhofer \& Rimac, 2009), include gender, education, personal experience, religion, and values. Specifically, women (Holland, Matthews, \& Schott, 2013), and those reporting higher levels of formal education (van den Akker, van der Ploeg, \& Scheepers, 2013), contact with homosexual men and women (Collier, Bos, \& Sandfort, 2012), lower levels of religiosity (Whitley, 2009), and liberal values (Steffens \& Wagner, 2004) are more accepting of homosexuality. Previous research indicates that explicit prejudice is negatively associated with gaydar accuracy, such that raters displaying the highest levels of explicit prejudice are least accurate. Furthermore, implicit prejudice is not related to gaydar accuracy and neither explicit nor implicit prejudice is associated with gaydar response bias (Rule, Tskhay, Brambilla, Riva, Andrzejewski, \& Krendl, 2015). The association between attitudes and rating confidence has not however been investigated. 
In summary, we aim to extend existing research by investigating the relationships between gaydar accuracy, bias, rating confidence, and attitudes towards homosexuality in a sample of homosexual and heterosexual men and women. Based on previous literature, we would expect above chance accuracy in detection of sexual orientation, which is likely to be separate from ratings of confidence. Further, we expect that negative attitudes towards homosexuality have an association with increased confidence, decreased accuracy, and have no relationship with bias towards labelling stimulus as homosexual.

\section{Method}

\section{Participants}

Men and women aged 18-65 years $\left(M_{\mathrm{age}}=28.70, S D=10.62\right)$ were recruited for a survey on "gaydar and attitudes towards homosexuality" via online research websites, social networking sites, and through advertising to students and staff at two British universities. Overall, 570 participants entered the survey, and 338 individuals completed the study (28 homosexual women, 153 heterosexual women, 59 bisexual women, 33 homosexual men, 55 heterosexual men, 10 bisexual men). For the purpose of analysing gaydar accuracy, bias, rating confidence and attitudes towards homosexuality, we included only heterosexual and homosexual participants who completed the whole survey $(N=269)$.

\section{Materials and Procedure}

Participants were first asked to report whether they considered themselves to be "primarily heterosexual”, "primarily homosexual”, or "primarily bisexual”. Participants then viewed a series of facial photographs (40 in total, 10 homosexual women, 10 heterosexual women, 10 homosexual men, and 10 heterosexual men), each featuring a self-identified homosexual or heterosexual man or woman. The images were retrieved from publicly available UK dating websites that provided open access to photographs and sexual orientation information. Forward facing British Caucasian headshot photographs with no facial 
adornments (e.g., glasses or piercings) were selected. The first 40 pictures meeting these criteria were selected, cropped from the shoulders, and made black and white for consistency. Photographs were presented one at a time in randomized order, and participants were asked to judge whether the person was "gay" or "straight". Participants were not provided with information about their rating accuracy or the proportion of heterosexual or homosexual faces in the sample. After each decision, participants were asked to rate how confident they were with their judgement $(1=$ not at all confident, $6=$ absolutely confident $)$. Finally, participants completed the Modern Homonegativity Scale (Morrison \& Morrison, 2002), a 24- item measure of attitudes towards homosexual men (12 items) and women (12 items). Two items were removed which were repeated in both subscales. Example items include "Many gay men use their sexual orientation so that they can obtain special privileges" and "Lesbians should stop shoving their lifestyle down other people's throats". Participants responded on a 5-point Likert scale $(1=$ strongly disagree to $5=$ strongly agree $)$, such that (after reverse coding) higher scores indicate negative attitudes to homosexual men and women. Cronbach's alphas were acceptable for each measure: attitudes towards homosexual men $(\alpha=.92)$; and attitudes towards homosexual women $(\alpha=.93)$.

\section{Results}

Homosexual and heterosexual faces were set as targets and lures respectively. We then calculated hit rates (HR; the probability of correctly categorizing a target as target) and false alarm rates (FAR; the probability of incorrectly categorizing a lure as target) for each individual and separately for female and male face stimuli. We computed HR and FAR for each individual and separately for female and male face stimuli. HR was calculated as the number of "gay" responses to homosexual stimuli divided by the total number of homosexual stimuli per gender. FAR was similarly calculated as the number of "gay" responses to heterosexual stimuli divided by the total number of heterosexual stimuli per gender. We 
corrected all 0 scores to .001 and all 1 scores to .999 to allow for calculation of the signal detection indices. $d^{\prime}$ was used as a bias-free measure of accuracy, whereas $c$ was used to measure response bias. Higher values of $c$ correspond to a more conservative criterion, i.e., the label "gay" is used less frequently, whereas lower values reflect a more liberal criterion.

To test whether there were any differences in rating accuracy and response bias across rater groups and picture types, we conducted two 2 (Sex of participant: male vs. female) x 2 (Sexual orientation of participant: homosexual vs. heterosexual) x 2 (Sex of picture: male vs. female) mixed ANOVAs. Dependent variables were $d$ ' and $c$. Table 1 displays $d$ ' and $c$ by sex and sexual orientation of the participant and sex of the picture. For the sake of brevity, we only report significant results here. For full results, please contact the first author.

For rating accuracy, the three-way interaction was statistically significant $(F(1,265)=$ $4.21, p=.041, \eta_{\mathrm{p}}^{2}=.02$ ), indicating that gaydar is associated with an interaction between the rater's sex, sexual orientation, and the sex of the stimulus picture. Further, there was a significant two-way interaction between sexual orientation of the rater, and the sex of the stimulus picture $\left(F(1,265)=4.28, p=.04, \eta_{\mathrm{p}}{ }^{2}=.01\right)$. Subsequent analyses $(t(60)=-3.07, p=$ $.003)$ revealed homosexual participant ratings of women $(M=.82, S D=.74)$ were more accurate than ratings of men $(M=.50, S D=.55)$.

When data for male and female participants were considered separately, comparisons $(t(32)=-3.41, p=.002)$ revealed homosexual men rated pictures of women $(M=.96, S D=$ .76) more accurately than pictures of men $(M=.49, S D=.55)$. Heterosexual women $(t(152)=$ $-2.03, p=.044)$ also rated pictures of women $(M=.78, S D=.71)$ more accurately than pictures of men $(M=.63, S D=.58)$. Finally, there was a main effect of sex of picture, $F(1,265)=6.09, p=.014, \eta_{\mathrm{p}}^{2}=.02$, such that accuracy was higher for female $(M=.75, S D=$ $.71)$ than for male $(M=.61, S D=.59)$ pictures. 
In terms of rating bias, there was a significant three-way interaction between the sex and sexual orientation of the participant and sex of picture, $F(1,265)=4.11, p=.044, \eta_{\mathrm{p}}{ }^{2}=$ .02 , and a significant two-way interaction between the sexual orientation of the participant and the sex of picture, $F(1,265)=3.94, p=.048, \eta_{\mathrm{p}}^{2}=.02$. No other main effects or interactions were significant. Overall, homosexual participants were significantly less likely $(t(60)=-2.32, p=.024)$ to categorise female pictures $(M=.20, S D=.24)$ as homosexual than male pictures $(M=.12, S D=.16)$. When data for male and female participants were considered separately $(t(32)=-3.20, p=.003)$, analyses revealed that homosexual men rating female pictures are less likely to label these as homosexual $(M=.26, S D=.22)$ than when rating male pictures $(M=.11, S D=.16)$.

\section{Table 1}

We then conducted a series of linear regressions to investigate whether attitudes towards homosexual men or women predict rating accuracy $\left(d^{\prime}\right)$, bias $(c)$, and confidence. Regressions were conducted separately for each participant group: heterosexual men; homosexual men; heterosexual women; homosexual women. These are shown in Table 2. For heterosexual men, negative attitudes towards homosexual men predicted response bias, $F(1$, $53)=7.10, p=.010$, and confidence when rating homosexual, $F(1,53)=8.34, p=.006$, and heterosexual, $F(1,53)=7.29, p=.009$, male targets. Negative attitudes towards homosexual men did not predict rating accuracy, $F(1,53)=.39, p=.535$. For homosexual male, heterosexual female, and homosexual female participants, attitudes towards homosexual men did not predict rating accuracy, bias, or confidence rating either heterosexual or homosexual men. Attitudes towards homosexual women did not predict rating accuracy, bias or confidence for any participant group (heterosexual men, homosexual men, heterosexual women, homosexual women). 


\section{Discussion}

Generally, we repeated the findings of previous studies (e.g., Brewer \& Lyons, 2016), suggesting that female photographs are easier to judge than male photographs. This was particularly evident for homosexual men and heterosexual women, who were more accurate when identifying sexual orientation in women, as opposed to in men. The similarity in homosexual men and heterosexual women mirrors the findings of studies on homosexuality and a behavioural and cognitive "shift" in the direction of the opposite sex (see Boothroyd, Cross, Gray, Coombes, \& Gregson-Curtis, 2011; LeVay, 2011). This could be related to perceptual vigilance to potential romantic rivals (see Maner \& Ackerman, 2015); although there currently is not much research to suggest that homosexual men could view the opposite sex as competitors in the mating market. The similarity in homosexual men and heterosexual women in accuracy of perception of female sexuality warrants further investigations.

The extent to which the ability to discriminate between heterosexual and homosexual targets reflects physical differences between these targets or the importance of characteristics (e.g. hairstyle) which may be manipulated remains unclear. For example, previous research suggests that homosexual women display smaller foreheads, mouths that are more puckered, and marginally more masculine face shapes than heterosexual women whereas homosexual men display shorter and smaller noses and more rounded jaws compared to heterosexual men (Skorska, Geniole, Vrysen, McCormick, \& Bogaert, 2015; Valentova, et al., 2014). Other researchers have documented the importance of features such as hairstyle which influences both rating accuracy and confidence (Rule, et al., 2008). In this context it is important to note that ratings were based on photographs taken from dating sites. Those using dating sites may present an ideal self (Ellison, Heino, \& Gibbs, 2006; Whitty, 2008). Whilst the current study did not include additional information (e.g. age, profession, personal interests) which can be manipulated on dating site profiles, site users often report that those online misrepresent their 
physical appearance (Gibbs, Ellison, \& Heino, 2006). Female photographs in particular are judged as less accurate depictions of the target by independent raters than male photographs (Hancock \& Toma, 2009). Furthermore, presentation may be influenced by a range of factors such as sexuality, culture, and femininity or masculinity (e.g. Ocampo, 2012). Additional research investigating ratings of other photograph types is recommended.

Although we did not replicate the negative trend between attitudes towards homosexuality and sexual orientation rating accuracy reported by Rule et al. (2015), we found some interesting relationships with confidence. Heterosexual men with a negative attitude were more confident (although not more accurate) when rating heterosexual and homosexual men. Further, heterosexual men who had negative attitudes were more likely to categorise photographs as homosexual when judging men's sexual orientation. This is an important finding, indicating that homophobic heterosexual men have cognitive biases that predispose them to use false positives when judging sexual orientation of other men. Humans have evolved cognitive mechanisms that make them err on the side of the least costly mistake when making decisions under uncertainty (Haselton \& Nettle, 2006). In terms of future social outcomes, homophobic men may consider it a safer option to make their judgements as false positives, and have a bias in labelling other men as homosexual. Additional research is recommended to investigate this speculative interpretation.

A number of limitations should be noted. First, the current study was conducted online, with the typical problems of self-selected sampling and drop-out rates affecting the sample characteristics (Birnbaum, 2004). However, internet-based research has been deemed as reliable as laboratory studies (Gosling, Vazire, Srivastava, \& John, 2004), and the benefits of online studies outweigh the costs (Gosling \& Mason, 2015), and may even help participants to answer more truthfully when completing questionnaires on sensitive topics such as homophobia. Second, the study was advertised to and English-speaking Western, 
Educated, Industrialised, Rich, and Democratic sample (WEIRD; Henrich, Heine, \& Norenzayan, 2010), not taking into account the wide variety of cross-cultural differences in acceptability of homosexuality (Adamczyk \& Cheng, 2015; European Commission, 2006). For example, though same-sex marriage is permitted in many countries (e.g. the United Kingdom, Canada); homosexuality is illegal in many countries (e.g. Iran, Yemen). Future research should consider the relationships between gaydar accuracy, bias, rating confidence, and attitudes towards homosexuality in a cross-cultural sample and investigate the relative impact of nationality or related factors such as religion (Rowatt, Tsang, Kelly, LaMartina, McCullers, \& McKinley 2006) and gender role stereotypes (Hoover \& Fishbein, 1999; Whitley, 2009). Initial findings in this area reveal cross-cultural variation in the speed and accuracy of sexual orientation categorisation, with those in cultures less accepting of homosexuality less likely to categorise targets as gay (Rule, Ishii, Ambady, Rosen, \& Hallett, 2011). Furthermore, ratings are more accurate when targets and raters are from the same culture (Valentova, Rieger, Havlicek, Linsenmeier, \& Bailey, 2011). Third, the relatively small sample of men recruited in the present study and less favourable attitudes towards homosexuality reported by men than by women suggest that it is particularly important for researchers to focus on male participants.

Consistent with previous research, the current study employed a standardised measure of explicit attitudes towards homosexuality (Morrison \& Morrison, 2002), which has demonstrable reliability and validity (e.g., Morrison, Kenny, \& Harrington, 2005). However, the scale measures overall attitudes towards homosexuality, rather than attitudes or behaviour directed at specific individuals. Future research may consider the extent to which gaydar accuracy, bias, and confidence are associated with willingness to behave in a pro-social or anti-social manner towards the target. Previous studies have suggested that attitudes towards homosexuality are associated with apparent transgressions of gender norms (Cohen, Hall, \& 
Tuttle, 2009). Raters often use perceived masculinity and femininity in female and male targets respectively to judge sexual orientation (Freeman, Johnson, Ambady, \& Rule, 2010; Rieger, Linsenmeier, Gygax, Garcia, \& Bailey, 2010), and the male and female images used in the present study were each rated as gender inverted in a previous study (Lyons et al., 2014). Therefore, future studies should obtain additional ratings of target masculinity and femininity to investigate the manner in which perceived masculinity or femininity may impact on rating confidence and homonegativity. This research should further control for heterosexual rater experience socialising with homosexual men and women which may increase rater accuracy (Brambilla, Riva, \& Rule, 2013).

To conclude, the current study investigated gaydar accuracy and bias, rating confidence, and attitudes towards homosexuality in homosexual and heterosexual men and women. Findings are consistent with previous research suggesting that female faces are judged more accurately than male faces. For heterosexual men, attitudes towards homosexual men predicted rating bias, such that men with more negative attitudes were more likely to label targets as homosexual when rating male pictures and were more confident when presented with photographs of heterosexual and homosexual men. Future research should consider these subjects further, and investigate the importance of culture and societal acceptance of homosexuality.

\section{References}

Adamczyk, A., \& Cheng, Y. H. A. (2015). Explaining attitudes about homosexuality in Confucian and non-Confucian nations: Is there a 'cultural' influence? Social Science Research, 51, 276-289 
Ambady, N., Hallahan, M., \& Conner, B. (1999). Accuracy of judgements of sexual orientation from thin slices of behavior. Journal of Personality and Social Psychology, 77, 538-547.

Birnbaum, M. H. (2004). Human research and data collection via the Internet. Psychology, 55, 803-832.

Boothroyd, L. G., Cross, C. P., Gray, A. W., Coombes, C., \& Gregson-Curtis, K. (2011). Perceiving the facial correlates of sociosexuality: Further evidence. Personality and Individual Differences, 50, 422-425.

Brambilla, M., Riva, P., \& Rule, N. O. (2013). Familiarity increases the accuracy of categorizing male sexual orientation. Personality and Individual Differences, 55, 193195.

Brewer, G., \& Lyons, M. (2016). Discrimination of sexual orientation: Accuracy and confidence. Personality and Individual Differences, 90, 260-264.

Buijs, L., Hekma, G., \& Duyvendak, J. W. (2009). Als ze maar van me afblijven: Een onderzoek naar antihomoseksueel geweld in Amsterdam [As they don't bugger me: An investigation of antigay violence in Amsterdam]. Amsterdam, The Netherlands: Amsterdam University Press.

Cohen, T. R., Hall, D. L., \& Tuttle, J. (2009). Attitudes toward stereotypical versus counterstereotypical gay men and lesbians. Journal of Sex Research, 46, 274-281.

Collier, K. L., Bos, H. M. W., \& Sandfort, T. G. M. (2012). Intergroup contact, attitudes toward homosexuality, and the role of acceptance of gender non-conformity in young adolescents. Journal of Adolescence, 35, 899-907.

Ellison, N., Heino, R., \& Gibbs, J. (2006). Managing impressions online: Self-presentation processes in the online dating environment. Journal of Computer-Mediated Communication, 11, 415-441. 
European Commission (2006). Eurobarometer 66: Public opinion in the European Union first results. Retrieved from http://ec.europa.eu/public_opinion/archives/eb/eb66/eb66_highlights_en.pdf

Falomir-Pichastor, J. M., \& Mugny, G. (2009). “I'm not gay...I'm a real man!”: Heterosexual men's gender self-esteem and sexual prejudice. Personality and Social Psychology Bulletin, 35, 1233-1243.

Freeman, J. B., Johnson, K. L., Ambady, N., \& Rule, N. O. (2010). Sexual orientation perception involves gendered facial cues. Personality and Social Psychology Bulletin, $36,1318-1331$.

Gaudino, R. P. (1994). Sounding gay: Pitch properties in the speech of gay and straight men. American Speech, 69, 30-57.

Gibbs, J.L., Ellison, N.B., \& Heino, R.D. (2006). Self-presentation in online personals: The role of anticipated future interaction, self-disclosure, and perceived success in Internet dating. Communication Research, 33, 1-26.

Gosling, S. D., \& Mason, W. (2015). Internet research in psychology. Psychology, 66, 877902.

Gosling, S. D., Vazire, S., Srivastava, S., \& John, O. P. (2004). Should we trust web-based studies? A comparative analysis of six preconceptions about internet questionnaires. American Psychologist, 59, 93-104.

Hancock, J.T., \& Toma, C.L. (2009). Putting your best face forward: The accuracy of online dating photographs. Journal of Communication, 59, 367-386.

Haselton, M. G., \& Nettle, D. (2006). The paranoid optimist: An integrative evolutionary model of cognitive biases. Personality and Social Psychology Review, 10, 47-66.

Henrich, J., Heine, S. J., \& Norenzayan, A. (2010). Most people are not WEIRD. Nature, 466, 29-29. 
Herek, G. M. (2002). Gender gaps in public opinion about lesbians and gay men. Public Opinion Quarterly, 66, 40-66.

Herek, G. M. (2004). Beyond "homophobia": Thinking about sexual prejudice and stigma in the twenty-first century. Sexuality Research \& Social Policy, 1, 6-24.

Herek, G. M. (2009). Hate crimes and stigma related experiences among sexual minority adults in the United States: Prevalence estimates from a national probability sample. Journal of Interpersonal Violence, 24, 54-74.

Holland, L., Matthews, T. L., \& Schott, M. R. (2013). “That's so gay”: Exploring college students' attitudes toward the LGBT population. Journal of Homosexuality, 60, 575595.

Hoover, R., \& Fishbein, H. D. (1999). The development of prejudice and sex role stereotyping in white adolescents and white young adults. Journal of Applied Developmental Psychology, 20, 431-448.

Hughes, S. M., \& Bremme, R. (2011). The effects of facial symmetry and sexually dimorphic facial proportions on assessments of sexual orientation. Journal of Social, Evolutionary, and Cultural Psychology, 5, 214-230.

Johnson, K. L., Gill, S., Reichman, V., \& Tassinary, L. G. (2007). Swagger, sway, and sexuality: Judging sexual orientation from body motion and morphology. Journal of Personality and Social Psychology, 93, 321-334.

LeVay, S. (2011). Gay, straight, and the reason why: The science of sexual orientation. New York: Oxford University Press.

Lyons, M., Lynch, A., Brewer, G., \& Bruno, D. (2014). Detection of sexual orientation (“Gaydar") by homosexual and heterosexual women. Archives of Sexual Behavior, $43,345-352$. 
Maner, J. K., \& Ackerman, J. M. (2015). Sexually selective cognition. Current Opinion in Psychology, 1, 52-56.

Morrison, M. A., \& Morrison, T. G. (2002). Development and validation of a scale measuring modern prejudice toward gay men and lesbian women. Journal of Homosexuality, 43, $15-37$.

Morrison, T. G., Kenny, P., \& Harrington, A. (2005). Modern prejudice toward gay men and lesbian women: Assessing the viability of a measure of modern homonegative attitudes with an Irish context. Genetic, Social, and General Psychology Monographs, $131,219-250$.

Ocampo, A.C. (2012). Making masculinity: Negotiations of gender presentation among Latino gay men. Latino Studies, 10, 448-472.

Rieger, G., Linsenmeier, J. A. W., Gygax, L., Garcia, S., \& Bailey, J. M. (2010). Dissecting "Gaydar": Accuracy and the role of masculinity-femininity. Archives of Sexual Behavior, 39, 124-140.

Rule, N. O., \& Ambady, N. (2008). Brief exposures: Male sexual orientation is accurately perceived at 50 ms. Journal of Experimental Social Psychology, 44, 1100-1105.

Rule, N. O., Ambady, N., Adams, R., \& Macrae, C. (2008). Accuracy and awareness in the perception and categorization of male sexual orientation. Journal of Personality and Social Psychology, 95, 1019-1028.

Rule, N. O., Ambady, N., \& Hallett, C. (2009). Female sexual orientation is perceived accurately, rapidly and automatically from the face and its features. Journal of Experimental Social Psychology, 45, 1245-1251.

Rule, N. O., Ishii, K., Ambady, N., Rosen, K. S., \& Hallett, K. C. (2011). Found in translation: Cross-cultural consensus in the accurate categorization of male sexual orientation. Personality and Social Psychology Bulletin, 37, 1499-1507. 
Rule, N. O., Tskhay, K. O., Brambilla, M., Riva, P., Andrzejewski, S. A., \& Krendl, A. C. (2015). The relationship between anti-gay prejudice and the categorization of sexual orientation. Personality and Individual Differences, 77, 74-80.

Rowatt, W., Tsang, J. A., Kelly, J., LaMartina, B., McCullers, M., \& McKinley, A. (2006). Associations between religious personality dimensions and implicit homosexual personality prejudice. Journal for the Scientific Study of Religion, 3, 397-406.

Skorska, M.N., Geniole, S.N., Vrysen, B.M., McCormick, C.M., \& Bogaert, A.F. (2015). Facial structure predicts sexual orientation in both men and women. Archives of Sexual Behavior, 44, 1377-1394.

Smyth, R., Jacobs, G., \& Rogers, H. (2003). Males voices and perceived sexual orientation: An experimental and theoretical approach. Language in Society, 32, 329-350.

Steffens, M., \& Wagner, C. (2004). Attitudes toward lesbians, gay men, bisexual women, and bisexual men in Germany. The Journal of Sex Research, 41, 137-149.

Stulhofer, A., \& Rimac, I. (2009). Determinants of homonegativity in Europe. Journal of Sex Research, 46, 24-32.

Sylva, F., Rieger, G., Linsenmeier, J. A. W., \& Bailey, J. M. (2010). Concealment of sexual orientation. Archives of Sexual Behavior, 39, 141-152.

Tabak, J. A., \& Zayas, V. (2012). The roles of featural and configural face processing in snap judgments of sexual orientation. Plos One, 7, e36671.

Talley, A. E., \& Bettencourt, B. A. (2008). Evaluations and aggression directed at a gay male target: The role of threat and antigay prejudice. Journal of Applied Social Psychology, $38,647-683$.

Toomey, R. B., \& Russell, S. T. (2013). The role of sexual orientation in school based victimization: A meta-analysis. Youth \& Society, 20, 1-26. 
Treas, J. (2002). How cohorts, education and ideology shaped a new sexual revolution: American attitudes toward nonmarital sex, 1972-1998. Sociological Perspectives, 45, 267-283.

Valentova, J. V., \& Havlicek, J. (2013). Perceived sexual orientation based on vocal and facial stimuli is linked to self-rated sexual orientation in Czech men. PLoS ONE, 8, e82417.

Valentova, J. V., Kleisner, K., Havlicek, J., \& Neustupa, J. (2014). Shape differences between the faces of homosexual and heterosexual men. Archives of Sexual Behavior, 43, 353-361.

Valentova, J., Rieger, G., Havlicek, J., Linsenmeier, J. A. W., \& Bailey, J. M. (2011). Judgments of sexual orientation and masculinity-femininity based on thin slices of behavior: A cross-cultural comparison. Archives of Sexual Behavior, 40, 1145-1152.

van den Akker, H., van der Ploeg, R., \& Scheepers, P. (2013). Disapproval of homosexuality: Comparative research on individual and national determinants of disapproval of homosexuality in 20 European countries. International Journal of Public Opinion Research, 25, 64-86.

Weinberg, G. (1972). Society and the Healthy Homosexual. New York: St Martin's.

Whitley, B. E. (2009). Religiosity and attitudes toward lesbians and gay men: A metaanalysis. International Journal for the Psychology of Religion, 19, 21-38.

Whitty, M.T. (2008). Revealing the 'real' me, searching for the 'actual' you: Presentations of self on an internet dating site. Computers in Human Behavior, 24, 1707-1723. 
Table 1: Means and Standard Deviations for the Accuracy Measure d', the Response Criterion Measure $c$, and Rating Confidence by Sex and Sexual Orientation of Participant, and Sex of Picture

\begin{tabular}{|c|c|c|c|c|c|c|}
\hline \multirow[b]{2}{*}{ Participant } & \multicolumn{2}{|c|}{$d^{\prime}$} & \multicolumn{2}{|c|}{$c$} & \multicolumn{2}{|l|}{ Confidence } \\
\hline & $\begin{array}{l}\text { Male } \\
\text { Photograph }\end{array}$ & $\begin{array}{l}\text { Female } \\
\text { Photograph }\end{array}$ & $\begin{array}{l}\text { Male } \\
\text { Photograph }\end{array}$ & $\begin{array}{l}\text { Female } \\
\text { Photograph }\end{array}$ & $\begin{array}{l}\text { Male } \\
\text { Photograph }\end{array}$ & $\begin{array}{l}\text { Female } \\
\text { Photograph }\end{array}$ \\
\hline \multicolumn{7}{|l|}{ Male } \\
\hline Heterosexual & $.67(.64)$ & $.57(.65)$ & $.19(.21)$ & $.17(.19)$ & $3.11(.86)$ & $3.22(.88)$ \\
\hline Homosexual & $.49(.55)$ & $.96(.76)$ & $.11(.16)$ & $.26(.22)$ & $3.39(.68)$ & $3.21(.72)$ \\
\hline \multicolumn{7}{|l|}{ Female } \\
\hline Heterosexual & $.63(.58)$ & $.78(.71)$ & $.19(.19)$ & $.19(.19)$ & $3.34(.73)$ & $3.36(.73)$ \\
\hline Homosexual & $.50(.57)$ & $.66(.69)$ & $.13(.17)$ & $.13(.24)$ & $3.23(.91)$ & $3.14(.88)$ \\
\hline
\end{tabular}


Table 2: Regression Analyses for Attitudes to Homosexuality and Rating Accuracy, Bias, and Confidence Rating Heterosexual and Homosexual Targets

\begin{tabular}{|c|c|c|c|c|c|c|}
\hline $\begin{array}{l}\text { Participant } \\
\text { Group }\end{array}$ & Predictor & Target & $\begin{array}{l}\text { Rating Accuracy } \\
\left(d^{\prime}\right)\end{array}$ & Rating Bias (c) & $\begin{array}{l}\text { Confidence Rating } \\
\text { Heterosexual } \\
\text { Targets }\end{array}$ & $\begin{array}{l}\text { Confidence Rating } \\
\text { Homosexual } \\
\text { Targets }\end{array}$ \\
\hline $\begin{array}{l}\text { Heterosexual } \\
\text { Men }\end{array}$ & $\begin{array}{l}\text { Attitudes to } \\
\text { Male } \\
\text { Homosexuality }\end{array}$ & Male & $\begin{array}{l}F(1,53)=.39, p= \\
.535\end{array}$ & $\begin{array}{l}F(1,53)=7.10, p= \\
.010\end{array}$ & $\begin{array}{l}F(1,53)=7.29, p= \\
.009\end{array}$ & $\begin{array}{l}F(1,53)=8.34, p= \\
.006\end{array}$ \\
\hline $\begin{array}{l}\text { Homosexual } \\
\text { Men }\end{array}$ & $\begin{array}{l}\text { Attitudes to } \\
\text { Male } \\
\text { Homosexuality }\end{array}$ & Male & $\begin{array}{l}F(1,31)=.02, p= \\
.903\end{array}$ & $\begin{array}{l}F(1,53)=.31, p= \\
.581\end{array}$ & $\begin{array}{l}F(1,31)=2.02, p= \\
.165\end{array}$ & $\begin{array}{l}F(1,31)=.1 .08, p \\
=.306\end{array}$ \\
\hline $\begin{array}{l}\text { Heterosexual } \\
\text { Women }\end{array}$ & $\begin{array}{l}\text { Attitudes to } \\
\text { Male } \\
\text { Homosexuality }\end{array}$ & Male & $\begin{array}{l}F(1,151)=.43, p \\
=.513\end{array}$ & $\begin{array}{l}F(1,151)=.00, p= \\
.996\end{array}$ & $\begin{array}{l}F(1,151)=.74, p= \\
.390\end{array}$ & $\begin{array}{l}F(1,151)=.1 .47, p \\
=.227\end{array}$ \\
\hline $\begin{array}{l}\text { Homosexual } \\
\text { Women }\end{array}$ & $\begin{array}{l}\text { Attitudes to } \\
\text { Male } \\
\text { Homosexuality }\end{array}$ & Male & $\begin{array}{l}F(1,26)=.05, p= \\
.823\end{array}$ & $\begin{array}{l}F(1,26)=.01, p= \\
.943\end{array}$ & $\begin{array}{l}F(1,26)=4.13, p= \\
.052\end{array}$ & $\begin{array}{l}F(1,26)=.4 .15, p \\
=.052\end{array}$ \\
\hline $\begin{array}{l}\text { Heterosexual } \\
\text { Men }\end{array}$ & $\begin{array}{l}\text { Attitudes to } \\
\text { Female } \\
\text { Homosexuality }\end{array}$ & Female & $\begin{array}{l}F(1,53)=.96, p= \\
.332\end{array}$ & $\begin{array}{l}F(1,53)=.46, p= \\
.499\end{array}$ & $\begin{array}{l}F(1,53)=2.45, p= \\
.124\end{array}$ & $\begin{array}{l}F(1,53)=3.36, p= \\
.072\end{array}$ \\
\hline $\begin{array}{l}\text { Homosexual } \\
\text { Men }\end{array}$ & $\begin{array}{l}\text { Attitudes to } \\
\text { Female } \\
\text { Homosexuality }\end{array}$ & Female & $\begin{array}{l}F(1,31)=4.114 \\
p=.05\end{array}$ & $\begin{array}{l}F(1,31)=.46, p= \\
.504\end{array}$ & $\begin{array}{l}F(1,31)=2.08, p= \\
.159\end{array}$ & $\begin{array}{l}F(1,31)=2.12, p= \\
.156\end{array}$ \\
\hline $\begin{array}{l}\text { Heterosexual } \\
\text { Women }\end{array}$ & $\begin{array}{l}\text { Attitudes to } \\
\text { Female } \\
\text { Homosexuality }\end{array}$ & Female & $\begin{array}{l}F(1,151)=.11, p \\
=.740\end{array}$ & $\begin{array}{l}F(1,151)=2.62, p \\
=.108\end{array}$ & $\begin{array}{l}F(1,151)=.00, p= \\
.968\end{array}$ & $\begin{array}{l}F(1,151)=.25, p= \\
.619\end{array}$ \\
\hline $\begin{array}{l}\text { Homosexual } \\
\text { Women }\end{array}$ & $\begin{array}{l}\text { Attitudes to } \\
\text { Female } \\
\text { Homosexuality }\end{array}$ & Female & $\begin{array}{l}F(1,26)=.19, p= \\
.663\end{array}$ & $\begin{array}{l}F(1,26)=.37, p= \\
.548\end{array}$ & $\begin{array}{l}F(1,26)=3.12, p= \\
.089\end{array}$ & $\begin{array}{l}F(1,26)=2.51, p= \\
.125\end{array}$ \\
\hline
\end{tabular}

